Pesq. Vet. Bras. 36(7):657-664, julho 2016 DOI: $10.1590 / \mathrm{S} 0100-736 \mathrm{X} 2016000700017$

\title{
Efeito de diferentes concentrações de melatonina em espermatozoides de carneiros sobre estresse oxidativo após criopreservação ${ }^{1}$
}

\author{
Wildelfrancys L. Souza ${ }^{2}$, Elenice A. Moraes ${ }^{3 *}$, Jonathan M.S. Costa ${ }^{2}$, Pedro H.F. \\ Sousa $^{4}$, Edilson S. Lopes Junior ${ }^{3}$, Raimundo P. Oliveira ${ }^{5}$ e Ricardo Toniolli ${ }^{2}$
}

\begin{abstract}
Souza W.L., Moraes E.A., Costa J.M.S., Souza P.H.F., Lopes Junior E.S., Oliveira R.P. \& Toniolli R. 2016. [Effect of different concentrations of melatonin to ram spermatozoa on oxidative stress after cryopreservation.] Efeito de diferentes concentrações de melatonina em espermatozoides de carneiros sobre estresse oxidativo após criopreservação. Pesquisa Veterinária Brasileira 36(7):657-664. Programa de Pós-Graduação em Ciência Animal, Fundação Universidade Federal do Vale do São Francisco, Rodovia 407 Km 12, Lote 543, Projeto Nilo Coelho C1, Petrolina, PE 56300-000, Brazil. E-mail: wilde@zootecnista.com.br

The aim was to evaluate the effect of adding different concentrations of melatonin in ram semen diluted after cryopreservation. Ten ejaculates were collected 0 from three adult ram $(n=30)$ by means of artificial vagina for sheep. The collected samples were diluted in Tris-egg yolk, to a final concentration $200 \times 10^{6} \mathrm{sptz} / \mathrm{mL}$ kept in water bath at $32^{\circ} \mathrm{C}$, and melatonin added as treatments: control; $100 \mathrm{pM} ; 100 \mathrm{nM} ; 100 \mu \mathrm{M}$ and $1 \mathrm{mM}$ melatonin. Then, the samples were cooled in a cold chamber at $5^{\circ} \mathrm{C}$ for two hours, in straws of $0.5 \mathrm{~mL}$ and sealed. They were stored under the liquid nitrogen vapor for 15 minutes to $8 \mathrm{~cm}$ of liquid blade and frozen with liquid nitrogen. Samples were analyzed for sperm motility, membrane integrity, acrosomal membrane, mitochondrial activity, oxidative stress and quantification of the binding capacity. The variables were subjected to analysis of variance and the means were compared by Tukey test at $5 \%$ probability. The total and progressive motility of thawed sperm were higher in samples treated with $100 \mathrm{pM}$ melatonin 662.99 and $45.07 \%$, respectively; $\mathrm{P}<0.05$ ) when compared to other treatments. The addition of different concentrations of melatonin in semen diluted with the exception of $1 \mathrm{mM}$ concentration, a higher percentage of cells with intact plasma membrane, as compared with the control $(\mathrm{P}<0.05)$. The percentage of sperm with acrosome membrane integrity was higher in the semen with $100 \mathrm{pM}$ melatonin $(\mathrm{P}<0.05)$ than the other treatments. The high mitochondrial activity was higher in spermatozoa treated with $100 \mathrm{pM}$ melatonin $(69.30 \%$; $\mathrm{P}<0.05$ ). Addition of $100 \mathrm{nM}$ melatonin reduced the amount of TBARS after cryopreservation $(2.84, \mathrm{P}<0.05)$ when compared with the other treatments. After thawing, the number of sperm which bind to the perivitelline membrane was higher in the melatonin treated with $100 \mathrm{pM}(155,73 ; \mathrm{P}<0.05)$. Therefore, melatonin addition the semen diluted can be useful to enhance the cryopreservation of sheep semen, improving fertilization rates through artificial insemination.
\end{abstract}

INDEX TERMS: Melatonin, antioxidant, freezing, ram, spermatozoa, stress, reactive oxygen species.

\footnotetext{
${ }^{1}$ Recebido em 7 de fevereiro de 2016.

Aceito para publicação em 23 de abril de 2016.

${ }^{2}$ Programa de Pós-Graduação em Ciências Veterinárias, Universidade Estadual do Ceará (UECE), Avenida Dr. Silas Muguba 1700, Campus do Itaperi, Fortaleza, CE 60740-000, Brasil.

${ }^{3}$ Programa de Pós-Graduação em Ciência Animal, Universidade Federal do Vale do São Francisco (Univasf), Rodovia 407, Km 12, Lote 543, Projeto
} 
RESUMO-- Objetivou-se avaliar o efeito da adição de diferentes concentrações de melatonina no sêmen diluído de carneiros após criopreservação. Foram coletados 10 ejaculados de três carneiros adultos $(n=30)$, por meio de vagina artificial para ovinos. Os ejaculados coletados foram diluídos em Tris-Gema de ovo, para a concentração final de $200 \times 10^{6} \mathrm{sptz} / \mathrm{mL}$, mantidos em banho maria a $32^{\circ} \mathrm{C}$, e a melatonina adicionada conforme os tratamentos: Controle; $100 \mathrm{pM} ; 100 \mathrm{nM} ; 100 \mu \mathrm{M}$ e $1 \mathrm{mM}$ de melatonina. Então, as amostras foram resfriadas em câmara fria a $5^{\circ} \mathrm{C}$ por duas horas, envasadas em palhetas de $0,5 \mathrm{~mL}$ e lacradas. Logo após, foram acondicionadas sob vapores do nitrogênio liquido, por 15 minutos, a $8 \mathrm{~cm}$ da lâmina líquida e congeladas com nitrogênio líquido. As amostras foram analisadas quanto à motilidade espermática, integridade da membrana plasmática, membrana acrossomal, atividade mitocondrial, quantificação do estresse oxidativo e a capacidade de ligação. As variáveis foram submetidas à análise de variância e as médias foram comparadas pelo teste de Tukey a $5 \%$ de probabilidade. A motilidade total e progressiva dos espermatozoides descongelados foi maior nas amostras tratadas com 100 pM de melatonina $(62,99$ e $45,07 \%$ respectivamente; $\mathrm{P}<0,05)$ quando comparado aos demais tratamentos. $\mathrm{A}$ adição das diferentes concentrações de melatonina no sêmen diluído, com exceção da concentração de $1 \mathrm{mM}$, apresentou maior percentual de células com membrana plasmática íntegra, quando comparadas com o controle $(\mathrm{P}<0,05)$. 0 percentual de espermatozoides com integridade da membrana do acrossoma foi maior no sêmen tratado com 100 pM de melatonina $(\mathrm{P}<0,05)$ do que nos demais tratamentos. A alta atividade mitocondrial foi maior nos espermatozoides tratados com $100 \mathrm{pM}$ de melatonina $(69,30 \%$; $\mathrm{P}<0,05)$. A adição de $100 \mathrm{nM}$ de melatonina reduziu a quantidade de TBARS após a criopreservação $(2,84 ; \mathrm{P}<0,05)$ quando comparado aos demais tratamentos. Após o descongelamento, o número de espermatozoides que se ligaram à membrana perivitelina foi maior nos tratados com $100 \mathrm{pM}$ de melatonina $(155,73 ; \mathrm{P}<0,05)$. Portanto, a adição de melatonina no sêmen diluído pode ser útil para aperfeiçoar a criopreservação do sêmen de ovinos, melhorando as taxas de fertilização por meio da inseminação artificial.

TERMOS DE INDEXAÇÃO: Melatonina, antioxidante, congelamento, espécies reativas de oxigênio, ovinos.

\section{INTRODUÇÃO}

O sucesso da criopreservação é parcial, uma vez que o processo de congelação/descongelação danifica cerca de $50 \%$ das células. Isso ocorre porque os espermatozoides ovinos apresentam alta sensibilidade ao estresse oxidativo em função das espécies reativas de oxigênio (EROs) geradas durante o processo de criopreservação, devido à baixa quantidade de antioxidantes e à alta concentração de ácidos graxos poliinsaturados na membrana plasmática (Bucak et al. 2007). Os ácidos graxos são essenciais para a manutenção funcional das células espermáticas (Henkel 2005), mas as altas taxas de EROs podem afetar as funções mitocondriais e, consequentemente a motilidade espermática (Du 2009).
A adição ao sêmen, de antioxidante, seja ele lipossolúvel ou hidrossolúvel, aumenta a tolerância espermática ao dano oxidativo, após descongelação. Além disso, os antioxidantes ainda possuem a capacidade de neutralizar os radicais livres que causam a peroxidação lipídica da membrana plasmática dos espermatozoides (Baumber et al. 2000). Sabe-se que os espermatozoides e o plasma seminal possuem enzimas e antioxidantes responsáveis pela remoção de quelante dos radicais livres. No entanto, isto não é suficiente para a proteção celular (Smith et al. 1996).

A melatonina é um antioxidante terminal, não enzimático e não pró-oxidativo (Tan et al. 2002), que possui a capacidade de detoxificação de radicais livres em concentrações fisiológicas e farmacológicas, sendo utilizada para prevenir as EROs (Reiter et al. 2007). A eficiência da função antioxidante da melatonina pode ser devido a sua capacidade quelante de radicais livres, ao estímulo sobre enzimas antioxidantes, à função da glutationa, que reduz a perda de elétrons de cadeia de transporte mitocondrial, e, finalmente, à ação sinérgica a outros antioxidantes (Reiter et al. 2007).

A adição de antioxidantes no meio de congelação protege os espermatozoides contra os danos causados pelos radicais livres (Maia et al. 2009), mas há poucos estudos que relatam o uso de melatonina no sêmen ovino. Este trabalho teve por objetivo avaliar o efeito da adição de diferentes concentrações de melatonina no sêmen diluído de carneiros após criopreservação.

\section{MATERIAL E MÉTODOS}

Aspectos Éticos. O presente estudo foi realizado após a aprovação institucional da Universidade Federal do Vale do São Francisco (Univasf), sob o protocolo no 0002/110414, estando de acordo com os princípios éticos de experimentação animal do Comitê de Ética e Deontologia em Estudos e Pesquisas da Univasf.

Local e período de execução. 0 experimento foi realizado durante os meses de maio à julho de 2014, no setor de Ovinocultura e no Centro de Pesquisa em Suínos, Espécies Nativas e Silvestre (CPSENS), localizados no Campus de Ciências Agrárias da Univasf, situados no munícipio de Petrolina-PE (latitude 09²3'55" Sul e a uma longitude $40^{\circ} 30^{\prime} 03^{\prime \prime}$ Oeste), estando a uma altitude de $376 \mathrm{~m}$, com precipitação média anual em torno de $300 \mathrm{~mm}$. A região apresenta temperatura média anual em torno dos $27^{\circ} \mathrm{C}$ e clima do tipo Bsh segundo a classificação de Köppen-Geiger (2007).

Animais. Foram utilizados três carneiros adultos, sendo dois da raça Dorper e um da raça Santa Inês, com idade de 2 a 4 anos, selecionados através de exame andrológico, onde todos apresentaram características espermáticas acima dos padrões mínimos, conforme estabelecido pelo Colégio Brasileiro de Reprodução Animal (CBRA 2013).

Os carneiros foram confinados em uma instalação contendo acesso a iluminação natural, com temperatura e umidade relativa média de $27,3^{\circ} \mathrm{C}$ e $47,5 \%$, respectivamente.

As baias apresentavam dimensão de $2 \times 3 \mathrm{~m}$ de área coberta e com área de solário de $2 \times 4 \mathrm{~m}$. Os carneiros foram mantidos isolados das fêmeas, recebendo água ad libitum e alimentação fornecida duas vezes ao dia, com dieta composta de capim elefante (Penissetum purpureum) picado, além de suplementação concentrada a base de farelo de milho, farelo de soja e mistura mineral. A relação volumoso:concentrado foi de 60:40 na forma de dieta total misturada, de acordo com as exigências para animais desta categoria segundo o National Research Council (NRC 2000). 
Coleta e processamento do sêmen. Foram coletados 10 ejaculados de cada carneiro ( $\mathrm{n}=30$ ), por meio de vagina artificial para ovinos (Vargina artificial ${ }^{\circledR}$, Minitub, Berlim, Alemanha). As coletas foram realizadas três vezes por semana para cada animal.

Após a coleta, o ejaculado foi transportado em uma caixa térmica para o CPSENS, mantido em banho-maria a $32^{\circ} \mathrm{C}$, e avaliado quanto a alterações macroscópicas, como, presença de urina ou sangue. Foram utilizados apenas ejaculados que atendiam aos padrões considerados normais pelo CBRA (CBRA 2013).

Após avaliação, os ejaculados aprovados foram subdivididos em cinco tubos de ensaio e diluídos em Tris-Gema de ovo e glicerol, conforme a concentração utilizada por Souza et al. (2015), para a concentração final de $200 \times 10^{6} \mathrm{sptz} / \mathrm{mL}$ e mantidos em banho maria a $32^{\circ} \mathrm{C}$.

A melatonina foi dissolvida em dimetilsulfóxido (DMSO) e tampão fosfato-salino (PBS), conforme Ishizuka et al. (2000). Para determinação dos tratamentos experimentais, a melatonina foi adicionada ao sêmen diluído, estabelecendo os tratamentos: controle (sem adição de melatonina); $100 \mathrm{pM} ; 100 \mathrm{nM} ; 100 \mu \mathrm{M}$ e $1 \mathrm{mM}$ de melatonina. A concentração final de DMSO em todos os tratamentos foi de $0,1 \%$.

Após adição da melatonina, as amostras de cada tratamento foram colocadas em Becker de $100 \mathrm{~mL}$ com água a $32^{\circ} \mathrm{C}$, ficando acima do volume das amostras e então acondicionadas em câmara fria a $5^{\circ} \mathrm{C}$ por duas horas. Depois, as amostras de cada tratamento foram envasadas em palhetas de $0,5 \mathrm{~mL}$ e lacradas com seladora (UltraSeal ${ }^{\circledR}$, Minitub, Berlim, Alemanha) e acondicionadas sob vapores do nitrogênio liquido, por 15 minutos, a $8 \mathrm{~cm}$ da lâmina líquida. Decorrido este tempo, as palhetas foram imersas no nitrogênio líquido $\left(-196^{\circ} \mathrm{C}\right)$ e estocadas em botijão criogênico para posterior análise.

Descongelação do sêmen. A descongelação foi realizada mergulhando-se as palhetas com as amostras de sêmen no descongelador automático $\left(\right.$ Cryofarm $^{\circledR}$, IMV, São Paulo, São Paulo, Brasil) por 30 segundos a $37^{\circ} \mathrm{C}$.

Avaliação da motilidade espermática. Duas palhetas de cada tratamento foram descongeladas conforme descrito acima para avaliação da motilidade espermática (total e progressiva), utilizando o sistema de análise computadorizada (CASA ${ }^{\circledR}$, Minitub, Berlin, Alemanha), equipado com o SpermVision ${ }^{\circledR}$. Alíquotas de $8 \mu \mathrm{L}$ de cada amostra por tratamento foram analisadas, individualmente, sobre lâmina pré-aquecidas, a $37^{\circ} \mathrm{C}$.

Avaliação da integridade da membrana plasmática. A integridade da membrana plasmática dos espermatozoides descongelados foi determinada pelo teste com sonda fluorescente. Para esta avaliação utilizou-se a associação de duas sondas fluorescentes, iodeto de propídio (IP) e Hoechst 33342 (H33342), conforme Graham et al. (1990). As amostras de cada tratamento foram colocadas em microtubos de 1,5mL após descongelação. Alíquotas de $10 \mu \mathrm{L}$ de cada tratamento foram colocadas em outro microtubo, no qual foi adicionado $2 \mu \mathrm{L}$ PI e de H33342, e incubadas em banho-maria a $37^{\circ} \mathrm{C}$ durante 8 minutos. Após este período de tempo, $10 \mu \mathrm{L}$ de cada amostra foi colocada entre lâmina e lamínula pré-aquecidas a $37^{\circ} \mathrm{C}$ e avaliadas em microscópio de fluorescência (AXIO Image $\mathrm{A} 2^{\circledR}$, Carl Zeiss, Berlim, Alemanha). Os espermatozoides com membrana plasmática lesada apresentavam o núcleo corado de rosa, e os de membrana plasmática intacta possuem o núcleo corado de azul.

Avaliação da integridade da membrana acrossomal. A integridade do acrossoma foi avaliada utilizando o fluorocromo (isoticianato de fluoresceína - FITC), conjugado a uma lecitina (peanut agglutinin - PNA) e associado a um fluorocromo que tem afinidade pelo DNA (iodeto de propídeo - IP) (Casey et al. 1993). Está técnica permite distinguir os espermatozoides vivos e/ou mortos com acrossoma intacto ou reagido.
Assim, $10 \mu \mathrm{L}$ de cada tratamento foi retirado e colocado em microtubo. Em seguida, foi adicionado $10 \mu \mathrm{L}$ de FITC-PNA e de PI, e depois incubado em banho maria a $37^{\circ} \mathrm{C}$ durante 20 minutos. Então, $10 \mu \mathrm{L}$ de cada amostra foi colocada entre lâmina e lamínula pré-aquecidas a $37^{\circ} \mathrm{C}$ e avaliada em microscópio de fluorescência (AXIO Image $\mathrm{A} 2^{\circledR}$, Carl Zeiss, Berlim, Alemanha), utilizando filtro de fluoresceína de excitação de $365 \mathrm{~nm}$ e de emissão de $420 \mathrm{~nm}$. Para cada campo selecionado, os espermatozoides foram visualizados inicialmente em campo claro e, posteriormente, em fluorescência. Onde um total de 200 células por amostra em campos aleatórios da lâmina foi contado.

O PNA possui a capacidade de se ligar à membrana acrossomal externa do espermatozoide com acrossoma reagido ou danificado. O IP penetra nos espermatozoides com membrana lesada, ligando-se ao DNA, indicando os espermatozoides vivos ou mortos. Dessa forma, os espermatozoides foram classificados em: espermatozoides mortos com acrossoma intacto (corados de vermelho do IP); espermatozoides mortos com acrossoma reagido ou danificado (corados de vermelho do IP, com região acrossomal corada de verde do FITC-PNA); espermatozoides vivos com acrossoma intacto (não observados em fluorescência, apenas em campo claro); espermatozoides vivos com acrossoma reagido ou danificado (corados de verde do FITC-PNA).

Avaliação da atividade mitocondrial. A atividade mitocondrial foi determinada conforme Hrudka (1987), onde $25 \mu \mathrm{L}$ de cada tratamento foi incubado com $25 \mu \mathrm{L}$ de DAB $(1 \mathrm{mg} / \mathrm{mL}$ de PBS), a $37^{\circ} \mathrm{C}$, por uma hora, na ausência de luz. Foram contados 200 espermatozoides por lâmina em microscópio óptico (DM $750^{\circledR}$, Leica Microsystems, Heerbrugg, Suiça), em objetiva de 100x, obedecendo à escala de quatro classes propostas por Hrudka (1987), onde: Classe I: células espermáticas com peça intermediária totalmente corada, alta atividade mitocondrial (DAB I); Classe II: células espermáticas com segmentos corados (ativos) e não corados (inativos), havendo predominância dos ativos (DAB II); Classe III: células espermáticas com segmentos corados (ativos) e não corados (inativos), havendo predominância dos inativos (DAB III); Classe IV: células espermáticas com peça intermediária totalmente descorada, sem atividade mitocondrial (DAB IV).

Avaliação da resistência ao estresse oxidativo. Para esta avaliação, as amostras nas palhetas foram descongeladas como descrito acima e o conteúdo esvaziado em tubos de ensaio. Em seguida, o crioprotetor foi removido através de dupla centrifugação (800G, 10 minutos) seguida de ressuspensão em solução fisiológica $(\mathrm{NaCl} 0,9 \%)$.

Após a centrifugação, 0,4 mL da suspensão foi transferido para um segundo tubo e a peroxidação lipídica foi induzida pela adição de $100 \mu \mathrm{L}$ de ácido ascórbico $(20 \mathrm{mM})$ e $100 \mu \mathrm{L}$ de sulfato de ferro ( $4 \mathrm{mM})$. Em seguida, a mistura permaneceu incubada por 120 minutos a $37^{\circ} \mathrm{C}$ (Gomez et al. 1998).

0 principal produto de peroxidação lipídica medido por este método foi o malondialdeído (MDA). As medições de MDA foram efetuadas em conformidade com um protocolo inicialmente descrito por Ohkawa et al. (1979). 0 método baseia-se na reação de duas moléculas de ácido tiobarbitúrico (TBA) com uma molécula de MDA, a altas temperaturas e baixo $\mathrm{pH}$, resultando em um cromogênio de cor rosa que pode ser quantificado com espectrofotômetro.

Após o período de 120 minutos, 0,5mL da mistura incubada e $1 \mathrm{~mL}$ de solução gelada de ácido tricloroacético a 10\%, foram misturadas, sendo centrifugadas (SL701 ${ }^{\circledR}$, Solab, Piracicaba, São Paulo, Brasil) a $5000 \mathrm{rpm}$ por 15 minutos a $15^{\circ} \mathrm{C}$, para a separação de proteínas precipitadas que pudessem interferir na leitura. Após a centrifugação, $1 \mathrm{~mL}$ do sobrenadante foi misturado em tubo de ensaio juntamente com $1 \mathrm{~mL}$ de TBA a $1 \%$ dissolvido em hidróxido de sódio $(0,05 \mathrm{~N}$ de $\mathrm{NaOH})$, preparado instantes antes 
de ser utilizado. 0 tubo contendo esta mistura foi incubado em banho-maria a $90^{\circ} \mathrm{C}$ por 15 minutos e resfriado imediatamente em banho de gelo, para interrupção da reação termo dependente.

As espécies reativas ao ácido tiobarbitúrico (TBARS) foram mensuradas em seguida, através da leitura em espectrofotômetro Q898DRM5 ${ }^{\circledR}$ (Quimis, São Paulo, SP, Brasil) em comprimento de onda de $532 \mathrm{~nm}$. Os resultados foram comparados com uma solução padrão, feita previamente, com MDA. A concentração de TBARS nas amostras foi expressa em micro molar de MDA por milhões de espermatozoides ( $\mu \mathrm{M}$ de MDA $/ 10^{6} \mathrm{sptz}$ ). Sendo assim, as amostras que apresentaram uma quantidade elevada de MDA, indicavam uma amostra bastante susceptível ao estresse oxidativo; este de ligação. A capacidade dos espermatozoides de ovino se ligar a membrana de oócitos foi avaliada utilizando a membrana perivitelina da gema de ovo de galinha (CEPM), descrito por Santos et al. (2015). Brevemente, a preparação das membranas perivitelinas (MPVs) foi realizada por meio da separação da gema de ovo da clara, e o excesso de clara removido com auxílio de um papel toalha. Em seguida, a gema de ovo ainda intacta, foi colocada sobre uma folha de parafilme, para facilitar o rompimento da membrana e sua lavagem com TALP (Graham et al. 1986) para retirada da gema de ovo. A membrana foi removida do parafilme e colocada em uma placa de Petri de vidro, onde foi lavada algumas vezes com TALP até a solução ficar clara e sem resíduo de gema de ovo. Em seguida, a MPV foi cuidadosamente aberta e cortada com lamina de bisturi em pequenos fragmentos $(1 \mathrm{x} 1 \mathrm{~cm})$, utilizando uma cubeta de vidro de espectrofotômetro. Cada fragmento de MPV cortado foi imerso em TALP colocados em tubos plásticos de $1 \mathrm{~mL}$.

Para realização do teste de ligação de membrana, os tubos de ensaio contendo as MPVs foram inseminados com 50.000 espermatozoides de cada tratamento. Após a inseminação, as MPVs foram incubadas a $37^{\circ} \mathrm{C}$ com uma atmosfera de $5 \%$ de $\mathrm{CO}_{2}$ por 90 minutos, sendo que a cada 30 minutos os tubos foram lentamente agitados para que a membrana permanecesse aberta. Passados 70 minutos de incubação, $10 \mu \mathrm{L}$ de Hoechst $33342(1 \mathrm{mg} / \mathrm{mL}$ em PBS) foi adicionado em cada tubo para corar de azul os espermatozoides. Após a incubação, cada membrana foi transferida para outro tubo contendo $1 \mathrm{~mL}$ de TALP para lavagem e remoção dos espermatozoides que não se ligaram, sendo repetido por 5 vezes esta etapa. Depois, as MPVs de cada tratamento foram abertas em lâmina e coberta com lamínula, e observada em microscópio de fluorescência (AXIO Image A2 ${ }^{\circledR}$, Carl Zeiss, Berlim, Alemanha), utilizando filtro de fluoresceína de excitação de 365 de emissão de $420 \mathrm{~nm}$.

O número de espermatozoides ligados à MPV foi determinado contando seis campos aleatórios de cada fragmento da MPV, e a eficiência de ligação à MPV foi calculada pela divisão do número total de espermatozoides ligados àquela particular MPV pelo número de espermatozoides ligados a mesma membrana pelo grupo controle.

Análise estatística. As variáveis foram submetidas à análise de variância e as médias foram comparadas pelo teste de Tukey a 5\% de probabilidade utilizando-se o programa SAS 9.2 20022008 by SAS Institute Inc., Cary, NC, USA.

\section{RESULTADOS}

Os efeitos das diferentes concentrações de melatonina sobre a motilidade espermática após a descongelação dos espermatozoides ovinos, estão apresentados no Quadro 1. A motilidade total e progressiva dos espermatozoides foi maior nas amostras tratadas com 100 pM de melatonina, quando comparado às demais concentrações testadas e ao controle (Quadro 1; $\mathrm{P}<0,05$ ).
Pode-se observar que os espermatozoides tratados com a adição de $100 \mathrm{pM}$ de melatonina, apresentaram maior percentual de membrana plasmática integra em comparação aos demais tratamentos (Quadro 2; $\mathrm{P}<0,05$ ). Todavia, a concentração de $1 \mathrm{mM}$ de melatonina resultou em percentual de integridade de membrana plasmática inferior as demais concentrações, inclusive ao tratamento controle (Quadro 2; $\mathrm{P}<0,05$ ).

Com relação à integridade acrossomal, a adição de 100 pM de melatonina ao sêmen diluído, proporcionou um maior percentual de espermatozoides com o acrossoma íntegro do que nos demais tratamentos (Quadro 2; $\mathrm{P}<0,05$ ).

Em relação à atividade mitocondrial, a melatonina demonstrou melhorar a qualidade espermática, pois houve maior percentual de espermatozoides com alta atividade mitocondrial (DAB I) após a adição de $100 \mathrm{pM}$ de melatonina comparado aos que tiveram a adição de $100 \mu \mathrm{M}, 1 \mathrm{mM}$ e ao controle (Quadro 3; $\mathrm{P}<0,05$ ). Observou-se que houve menor porcentagem de células espermáticas ativas (DAB II) no sêmen diluído ao qual foi adicionado de $100 \mathrm{pM}$ de melatonina (Quadro 3; $\mathrm{P}<0,05$ ). Entretanto, apesar do DAB II ter sido menor, a adição de $100 \mathrm{pM}$ também promoveu menor percentual de células inativas (DAB III) e sem atividade mitocondrial (DAB IV) quando comparado aos demais tratamentos (Quadro 3; $\mathrm{P}<0,05$ ).

Observou-se que a adição de $100 \mathrm{nM}$ de melatonina no sêmen diluído, produziu menor quantidade de TBARS após a criopreservação, quando comparado aos demais tratamentos utilizados (Quadro 4; $\mathrm{P}<0,05$ ). Por outro lado, a quantidade de TBARS gerada nas concentrações de $100 \mathrm{pM}$ e $100 \mu \mathrm{M}$, apresentaram uma produção de espécies reativas menor que a concentraçao de $1 \mathrm{mM}$ e o controle (Quadro 4; $\mathrm{P}<0,05)$.

Em relação à capacidade dos espermatozoides se li-

Quadro 1. Motilidade total e progressiva de espermatozoides descongelados de ovinos após adição de diferentes concentrações de melatonina no sêmen diluído

\begin{tabular}{|c|c|c|}
\hline \multirow[t]{2}{*}{ Concentrações de melatonina } & \multicolumn{2}{|c|}{ Motilidade } \\
\hline & Total & Progressiva \\
\hline Controle & $57,30 \pm 5,83^{\mathrm{B}}$ & $38,10 \pm 6,82^{\mathrm{B}}$ \\
\hline $100 \mathrm{pM}$ & $62,99 \pm 5,01^{\mathrm{A}}$ & $45,07 \pm 5,52^{\mathrm{A}}$ \\
\hline $100 \mathrm{nM}$ & $56,70 \pm 5,72^{\mathrm{B}}$ & $38,46 \pm 6,62^{\mathrm{B}}$ \\
\hline $100 \mu \mathrm{M}$ & $58,20 \pm 5,94^{\mathrm{B}}$ & $39,76 \pm 5,61^{B}$ \\
\hline $1 \mu \mathrm{M}$ & $46,89 \pm 5,87^{\mathrm{C}}$ & $28,95 \pm 5,24^{C}$ \\
\hline
\end{tabular}

$\overline{\mathrm{A}, \mathrm{B}, \mathrm{C}}$ Médias seguidas de letras diferentes na mesma coluna diferem entre si pelo teste de Tukey $(\mathrm{P}<0,05)$. Os dados são expressos como média \pm D.P.

Quadro 2. Percentagem de integridade da membrana plasmática (iMP) e acrossomal (iMA) de espermatozoides descongelados de ovinos após adição de diferentes concentrações de melatonina no sêmen diluído

\begin{tabular}{ccc}
\hline Concentrações de mlatonina & iMP & iMA \\
\hline Controle & $22,04 \pm 3,25^{\mathrm{BC}}$ & $78,06 \pm 5,14^{\mathrm{C}}$ \\
$100 \mathrm{pM}$ & $37,00 \pm 2,97^{\mathrm{A}}$ & $92,19 \pm 5,35^{\mathrm{A}}$ \\
$100 \mathrm{nM}$ & $27,18 \pm 3,12^{\mathrm{B}}$ & $89,00 \pm 5,28^{\mathrm{AB}}$ \\
$100 \mu \mathrm{M}$ & $23,68 \pm 3,45^{\mathrm{BC}}$ & $86,48 \pm 5,45^{\mathrm{AB}}$ \\
$1 \mu \mathrm{M}$ & $18,80 \pm 3,14^{\mathrm{C}}$ & $84,46 \pm 5,10^{\mathrm{B}}$
\end{tabular}

$\overline{\mathrm{A}, \mathrm{B}, \mathrm{C}}$ Médias seguidas de letras diferentes na mesma coluna diferem entre si pelo teste de Tukey $(\mathrm{P}<0,05)$. Os dados são expressos como média \pm D.P. 
Quadro 3. Atividade mitocondrial dos espermatozoides descongelados de ovinos após adição de diferentes concentrações de melatonina no sêmen diluído

\begin{tabular}{ccccc}
\hline $\begin{array}{c}\text { Concentrações } \\
\text { de melatonina }\end{array}$ & DAB I (\%) & DAB II (\%) & DAB III (\%) & DAB IV(\%) \\
\hline Controle & $58,60 \pm 6,41^{\mathrm{B}}$ & $22,05 \pm 3,98^{\mathrm{A}}$ & $10,3 \pm 2,79^{\mathrm{A}}$ & $9,05 \pm 3,73^{\mathrm{A}}$ \\
$100 \mathrm{pM}$ & $69,30 \pm 5,35^{\mathrm{A}}$ & $16,96 \pm 2,87^{\mathrm{B}}$ & $7,41 \pm 3,83^{\mathrm{B}}$ & $6,33 \pm 2,94^{\mathrm{B}}$ \\
$100 \mathrm{nM}$ & $64,46 \pm 5,72^{\mathrm{AB}}$ & $19,65 \pm 3,01^{\mathrm{AB}}$ & $7,78 \pm 2,54^{\mathrm{AB}}$ & $8,11 \pm 2,48^{\mathrm{AB}}$ \\
$100 \mu \mathrm{M}$ & $62,51 \pm 5,06^{\mathrm{B}}$ & $20,83 \pm 2,33^{\mathrm{AB}}$ & $8,46 \pm 3,66^{\mathrm{AB}}$ & $8,20 \pm 2,38^{\mathrm{AB}}$ \\
$1 \mu \mathrm{M}$ & $61,68 \pm 5,83^{\mathrm{B}}$ & $21,46 \pm 2,47^{\mathrm{AB}}$ & $8,86 \pm 2,62^{\mathrm{AB}}$ & $8,00 \pm 2,49^{\mathrm{AB}}$
\end{tabular}

$\overline{\mathrm{A}, \mathrm{B}}$ Médias seguidas de letras diferentes na mesma coluna diferem entre si pelo teste de Tukey $(\mathrm{P}<0,05)$.

Quadro 4. Número de espécies reativas ao acido tiobarbitúrico (TBARS) geradas em espermatozoides descongelados de ovinos após adição de diferentes concentrações de melatonina no sêmen diluído

\begin{tabular}{cc}
\hline Concentrações de melatonina & TBARS $(\mu \mathrm{M}$ de MDA/106 sptz $)$ \\
\hline Controle & $3,58 \pm 1,54^{\mathrm{A}}$ \\
$100 \mathrm{pM}$ & $3,17 \pm 1,46^{\mathrm{AB}}$ \\
$100 \mathrm{nM}$ & $2,84 \pm 1,99^{\mathrm{B}}$ \\
$100 \mu \mathrm{M}$ & $3,24 \pm 1,44^{\mathrm{AB}}$ \\
$1 \mu \mathrm{M}$ & $3,66 \pm 1,68^{\mathrm{A}}$
\end{tabular}

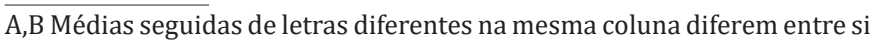
pelo teste de Tukey $(\mathrm{P}<0,05)$. Os dados são expressos como média \pm D.P.

Quadro 5. Número de espermatozoides descongelados de ovinos ligados à membrana perivitelina de gema de ovo (NEL) e sua eficiência de ligação (EFL) após adição de diferentes concentrações de melatonina no sêmen diluído

\begin{tabular}{ccc}
\hline Concentrações de melatonina & NEL & EFL \\
\hline Controle & $115,70 \pm 5,82^{\mathrm{D}}$ & 1,0 \\
$100 \mathrm{pM}$ & $155,73 \pm 3,24^{\mathrm{A}}$ & 1,34 \\
$100 \mathrm{nM}$ & $144,86 \pm 4,66^{\mathrm{B}}$ & 1,25 \\
$100 \mu \mathrm{M}$ & $141,83 \pm 5,62^{\mathrm{B}}$ & 1,22 \\
$1 \mu \mathrm{M}$ & $125,93 \pm 4,52^{\mathrm{C}}$ & 1,09
\end{tabular}

$\overline{\mathrm{A}, \mathrm{B}, \mathrm{C}, \mathrm{D} \text { Médias seguidas }}$ de letras diferentes na mesma coluna diferem entre si pelo teste de Tukey $(\mathrm{P}<0,05)$. Os dados são expressos como média \pm D.P.

garem à membrana perivitelina da gema de ovo, após o processo de congelação/descongelação, observou-se que o número de espermatozoides descongelados que se ligaram, foi maior para os que receberam a adição de $100 \mathrm{pM}$ de melatonina no sêmen diluído, em comparação aos demais grupos tratados e o controle (Quadro 5; $\mathrm{P}<0,05$ ).

\section{DISCUSSÃO}

0 efeito antioxidante da melatonina em vários tipos de células tem sido frequentemente explicado devido a sua capacidade de neutralizar uma grande quantidade de radicais livres tóxicos (Peyrot \& Ducrocq 2008, Hardeland et al. 2009) e influenciar a expressão gênica de enzimas antioxidantes, aumentando os níveis de RNA mensageiro e de proteínas dessas enzimas (Reiter et al. 2000).

Vários autores têm relatado que a melatonina apresenta efeito benéfico sobre a preservação de espermatozoides de mamíferos, melhorando seus parâmetros funcionais (Rao \& Gangadharan 2008, Casao et al. 2010, Du Plessis et al. 2010, Ashrafi et al. 2013). Deste modo, a análise dos diferentes pa- râmetros seminais, como: motilidade espermática, integridade da membrana plasmática e acrossomal, atividade mitocondrial e a produção de MDA, são importantes para predizer a qualidade espermática para posterior utilização do sêmen congelado/descongelado em inseminação artificial. No estudo atual, os resultados mostraram que a adição de melatonina no sêmen diluído sobre esses parâmetros avaliados, resultou em efeitos benéficos entre os diferentes grupos de tratamentos, protegendo as estruturas de forma eficiente.

Os parâmetros de motilidade total e progressiva aumentaram com a inclusão de 100 pM melatonina no sêmen diluído. Isso demonstra que a motilidade espermática pode ser preservada como consequência do efeito protetor da melatonina sobre as mitocôndrias dos espermatozoides. Além disso, o efeito protetor da melatonina contra os danos ocasionados à célula espermática durante a criopreservação ocorreu de forma dose dependente. Nesse estudo, foram utilizadas diferentes concentrações de melatonina no sêmen diluído, sendo que a de $1 \mathrm{mM}$ resultou em um declínio no percentual de motilidade espermática, sugerindo que doses elevadas desse antioxidante podem inibir a fosforilação oxidativa.

Os espermatozoides de mamíferos são particularmente vulneráveis ao estresse oxidativo (Khalil et al. 2013), devido à composição da membrana plasmática e à exposição às mudanças drásticas de temperatura, os quais são muitas vezes, expostos, especialmente quando usados em técnicas de reprodução artificial com sêmen criopreservado (Mata-Campuzano et al. 2012). Alterações morfológicas na membrana plasmática durante a criopreservação levam à peroxidação da bicamada lipídica, por conta da elevada produção de EROs, produzidas durante o processo de congelação-descongelação (Sariozkan et al. 2010). Os resultados demonstram que a adição de melatonina no diluente de congelação, neutralizou os efeitos adversos do processo de congelação-descongelação sobre a integridade da membrana plasmática (100pM) dos espermatozoides de carneiros.

Esse efeito protetor, está associado com a redução da peroxidação lipidica (Ashrafi et al. 2013) e a inibição da ruptura na membrana, causada durante a redução de temperatura (Lei et al. 2004). Essa proteção refere-se ao aumento na capacidade antioxidante total e a elevação da atividade das enzimas antioxidantes, após o tratamento com a melatonina. Ela é capaz de estimular várias enzimas (superóxido dismutase, glutationa peroxidade e catalase), envolvidas no metabolismo das EROs, proporcionando, assim, uma melhor preservação da integridade da membrana plasmática.

Danos à integridade da membrana plasmática provocam um aumento na permeabilidade da membrana e uma redução na capacidade do espermatozoide em controlar as concentrações intracelulares de íons que, por sua vez, estão envolvidos na motilidade espermática (Baumber et al. 2000). Dessa forma, observou-se que a melatonina em pequenas concentrações exerce a função protetora contra a peroxidação da membrana plasmática das células espermáticas, durante a criopreservação, preservando assim, a sua permeabilidade e consequentemente a motilidade espermática. 
0 percentual de integridade acrossomal dos espermatozoides que receberam adição de $100 \mathrm{pM}$ de melatonina, foi mais elevado em relação aos demais tratamentos no qual a melatonina foi adicionada. Isso pode ter sido devido ao efeito estimulatório da melatonina, quando em pequenas concentrações, sobre a atividade das enzimas envolvidas na defesa antioxidante. Além do que, com base nos resultados do efeito da melatonina sobre a integridade acrossomal, observou-se que a adição na concentrações de $1 \mathrm{mM}$, não foi eficiente na proteção contra danos ao acrossoma espermático.

A variação do efeito observado com as diferentes concentrações de melatonina pode ser explicada pelo fato de que quantidades excessivas de antioxidante, causam alta fluidez da membrana plasmática, acima do ponto desejado, deixando os espermatozoides mais propensos a danos no acrossoma (Ashrafi et al. 2011, Shoae \& Zamiri 2008). Diante disso, a concentração de antioxidante adicionado ao diluente deve ser considerada, devido às possíveis alterações na condição fisiológica do diluente seminal que ela pode causar. Adicionalmente, sabe-se que elevados níveis de melatonina podem ainda, prejudicar o desenvolvimento ou a maturação dos espermatozoides, reduzindo o seu potencial fecundante (Ashrafi et al. 2013).

Nas células espermáticas, existe um grande número de mitocôndrias densamente compactadas em torno das fibras densas que envolvem o axonema, as quais produzem o trifostato de adenosina (ATP), por respiração aeróbica (Perumal et al. 2013). Tem sido relatado (Aitken \& Clarkson 1987) que o axonema e as mitocôndrias na peça intermediária, podem ser danificados por níveis elevados de EROs. Estudos mostram que a melatonina pode estabilizar e proteger as mitocôndrias através de vários mecanismos (Martín et al. 2000; Lopez et al. 2009). Primeiro, as propriedades antioxidante e removedora de radicais livres da indoleamina protegem a organela dos danos oxidativos (Martín et al. 2000). Segundo, a melatonina aumenta a atividade dos complexos respiratórios I, III e IV da cadeia de transporte de elétrons, reduzindo o fluxo de oxigênio e melhorando a eficiência respiratória das mitocôndrias (Lopez et al. 2009) e aumentando a síntese de ATP em condições normais e estressantes (Acuna-Castroviejo et al. 2002).

Como a melatonina é uma molécula anfifílica, ela é capaz de atravessar as membranas celulares com facilidade e, assim, atingir compartimentos subcelulares, podendo acumular-se em concentrações elevadas nas organelas, como a mitocôndria (Venegas et al. 2012). Com essa propriedade, a melatonina é capaz de eliminar os radicais livres gerados na mitocôndria, além de reduzir a fuga de elétrons a partir da cadeia respiratória, diminuindo a formação de EROs (Leon et al. 2004). A melatonina, além de ser capaz de proteger as mitocôndrias dos danos oxidativos, reduzindo o consumo de oxigênio, é capaz de melhorar o potencial da membrana e a produção do ânion superóxido, mantendo, ao mesmo tempo, a produção de ATP (Lopez et al. 2009).

Com base nessas informações, pode-se sugerir que devido a maior atividade mitocondrial observada nas amostras com 100pM de melatonina, a produção e o niveis de ATP intracelular são mais elevados, sendo atribuído a proteção exercida pela melatonina nas mitocôndrias espermáticas con- tra as injurias que podem prejudicar a produção de ATP, bem como as estruturas flagelares, reduzindo assim, à geração de EROs. Nos espermatozoides, a produção de ATP supre várias atividades celulares e eventos bioquímicos, necessários para que a fecundação seja bem sucedida, tais como a capacitação, reação acrossômica e a motilidade espermática (Miki 2007). Dessa forma, a maior disponiblidade de ATP contribuiu para uma maior motilidade espermática, observada após a criopreservação nas amostras com $100 \mathrm{pM}$ de melatonina em comparação com os demais grupos experimentais.

No que se refere a geração de EROs, a produção de MDA vem sendo utilizada para determinar a peroxidação lipídica em vários tipos de células, incluindo as espermáticas (Sikka 1996). O estresse oxidativo é um fator crítico na morte das células espermáticas durante o processo de criopreservação (Sikka 1996). Os espermatozoides são muito sensíveis aos seus efeitos, e a sua capacidade fecundante é prejudicada devido à apoptose e aos danos no DNA (Martinez-Pastor et al. 2009).

A verificação da produção de TBARS é um método simples de quantificar os danos oxidativos nas células in situ (Dawn-Linsley et al. 2005). No presente estudo, a adição de 100nM de melatonina no sêmen diluído, foi capaz de diminuir a susceptibilidade das células ao estresse oxidativo, visto que, a produção de TBARS foi menor, em relação aos demais tratamentos, sugerindo que a melatonina em pequenas concentrações, pode reduzir a peroxidação lipídica nas células espermáticas de carneiros, devido a sua natureza anfifílica e a propriedade antioxidante, além do efeito estimulatório sobre a atividade das enzimas envolvidas na defesa antioxidante.

Todavia, a concentração de melatonina a ser adicionada na terapia antioxidante é de extrema importância, devendo ser considerada. Nesse estudo, observa-se que o tratamento antioxidante com a concentração excessiva, $1 \mathrm{mM}$ de melatonina, resultou em efeito deletério, com produção de TBARS superior as demais concentrações e semelhante ao tratamento controle. Assim, as altas concentrações de melatonina no sêmen diluído, em contato com a célula espermática, podem levar ao bloqueio de importantes funções fisiológicas, resultanto no aumento do estresse oxidativo.

Devido às semelhanças moleculares entre a zona pelúcida do oócito e a membrana perivitelina, os espermatozoides de muitas espécies podem se ligar a ela (Moraes et al. 2015), inclusive os de ovinos. Por outro lado, ensaios de ligação de MPV podem também ser úteis para determinar interações entre os espermatozoides e o oócito, uma parte importante do processo de fecundação (Moraes et al. 2015). A melhora na função espermática com a adição de melatonina, observada no sêmen descongelado, estimulou uma maior capacidade de ligação em todas as concentrações utilizadas nesse estudo, quando comparada ao controle, sendo a mais eficaz a de 100 pM. Embora, os testes in vitro não possam avaliar com total confiabilidade o potencial fecundante dos espermatozoides (Moce \& Graham 2008), a obtenção de dados de fecundação in vivo pode ser muito cara e demorada (Moraes et al. 2015). Portanto, a realização de novos testes in vitro que permitam avaliar os atributos necessários para os espermatozoides fecundarem, pode ser muito útil para predizer a 
possibilidade de fecundidade (Moraes et al. 2015).

Os dados apresentados neste estudo mostraram resultados positivos quanto à adição de melatonina no sêmen diluído, visando promover melhoria da qualidade espermática, comprovando, através dos testes laboratoriais in vitro, o aumento da motilidade, a preservação da integridade das membranas plasmática e acrossomal, o aumento da atividade mitocondrial, a redução do estresse oxidativo e a capacidade dos espermatozoides de se ligarem à MPV, consequentemente, uma possível melhoria do potencial fertilizante de espermatozoides descongelados de carneiros.

Vale ressaltar que os resultados desse estudo mostraram que a concentração de melatonina utilizada é de importância crucial para obter o efeito protetor desejado. Em termos gerais, os resultados obtidos mostram que a adição de 100 pM de melatonina no diluente para criopreservação, favorece a redução do efeito deletério do estresse oxidativo ocasionado pela crioinjúria na célula espermática, durante os procedimentos de congelação/descongelação. Por outro lado, o aumento na concentração de melatonina, não foi acompanhado por um aumento adicional dos efeitos benéficos da indoleamina sobre as células espermáticas.

\section{CONCLUSÕES}

Em conclusão, este estudo demonstrou que a adição de melatonina ao sêmen diluído, em baixas concentrações, apresentou efeitos benéficos sobre os espermatozoides de carneiros, protegendo-os das crioinjúrias durante o período de criopreservação.

Esses resultados sugerem que os efeitos protetores da melatonina sobre os espermatozoides são particularmente eficazes durante a criopreservação do sêmen e estão associados à propriedade antioxidante da referida substância, juntamente com a redução da lipoperoxidação e o aumento da atividade das enzimas antioxidantes.

Portanto, a adição de melatonina no sêmen diluído pode ser útil para aperfeiçoar a criopreservação do sêmen de ovinos, melhorando as taxas de fertilização por meio da inseminação artificial.

Agradecimentos.- A Coordenação de Aperfeiçoamento de Pessoal de Nível Superior (Capes), pela bolsa de estudos. Ao Centro de Pesquisa em Suínos, Espécies Nativas e Silvestre (CPSENS) da Univasf por toda infraestrutura e suporte para a realização da pesquisa.

\section{REFERÊNCIAS}

Acuna C.D., Escames G., Carazo A., Leon J., Khaldy H. \& Reiter R.J. 2002. Melatonin, mitochondrial homeostasis and mitochondrial-related diseases. Curr. Top. Med. Chem. 2(2):133-151.

Aitken R.J. \& Clarkson J.S. 1987. “Cellular basis of defective sperm function and its association with the genesis of reactive oxygen species by human spermatozoa". J. Reprod. Ferti. 81(2):459-469.

Ashrafi I., Kohram H. \& Ardabili F.F. 2013. Antioxidative effects of melatonin on kinetics, microscopic and oxidative parameters of cryopreserved bull spermatozoa. Anim. Reprod. Sci. 139(1/4):25-30.

Ashrafi I., Kohram H., Naijian H., Bahreini M. \& Mirzakhani H. 2011. Effect of controlled and uncontrolled cooling rate on motility parameters of cryopreserved ram spermatozoa. BMC Res. Notes 4:547.

Baumber J., Bll B.A. \& Gravance C.G. 2000. The effect of reactive oxygen species on equine sperm motility, viability, acrossomal integrity, mito- chondrial membrane potential and membrane lipid peroxidation. J. Androl. 21(6):895-902.

Bucak M., Ateşşahin A., Varişli O., Yüce A., Tekin N. \& Akçay A. 2007. The influence of trehalose, taurine, cysteamine and hyaluronan on ram semen: Microscopic and oxidative stress parameters after freeze-thawing process. Theriogenology 67(5):1060-1067.

Casao A., Vega S., Palacín I., Pérez-Pe R., Laviña A., Quintín F.J., Sevilla E., Abecia J.A., Cebrián-Pérez J.A., Forcada F. \& Muiño-Blanco T. 2010. Effects of melatonin implants during non-breeding season on sperm motility and reproductive parameters in Rasa Aragonesa rams. Reprod. Domest. Anim. 45(3):425-432.

Casey P.J., Hillman R.B., Robertson K.R., Yudin A.I., Liu I.K.M. \& Drobins E.Z. 1993. Validation of an acrosomal stain for equine sperm that differentiates between living and dead sperm. J. Androl. 14(4):289-297.

CBRA 2013. Manual para Exame Andrológico e Avaliação de Sêmen Animal. 3a ed. Colégio Brasileiro de Reprodução Animal, Belo Horizonte. 104p.

Dawn-Linsley M., Ekinci F.J., Ortiz D., Rogers E. \& Shea T.B. 2005. Monitoring thiobarbituric acid-rective substances (TBARs) as an assay for oxidative damage in neuronal cultures and central nervous system. J. Neurosci. Methods 141(2):219-222.

Du L.Y., Cao S.X., Guo W. \& Liu T.Z. 2009. Antioxidation of melatonin on boar semen preservation, Jian. J. Agric. Sci. 25(2):315-319.

Du Plessis S.S., Hagenaar K. \& Lampiao F. 2010. The in vitro effects of melatonin on human sperm function and its scavenging activities on $\mathrm{NO}$ and ROS. Andrologia 42(2):112-116.

Gomez E., Irvine D.S. \& Aitken R.J. 1998. Evaluation of a spectrophotometric assay for the measurement of malondialdehyde and 4- hydroxyalkenals in human spermatozoa: relationships with semen quality and sperm function. Int. J. Androl. 21(2):81-94.

Graham J.K., Foote R.H. \& Parrish J.J. 1986. Effect of dilauroyphosphatidylcholine on the acrosome reaction and subsequent penetration of bull sperm into zona-free hamster eggs. Biol. Reprod. 35(2):413-424.

Graham J.K., Kunze E. \& Hammerstedt R.H. 1990. Analysis of sperm cell viability, acrosomal integrity, and mitochondrial function using flow cytomitry. Biol. Reprod. 43(1):55-64.

Hardeland R., Tan D.X. \& Reiter R.J. 2009. Kynuramines, metabolites of melatonin and other indoles: The resurrection of an almost forgotten class of biogenic amines. J. Pineal Res. 47(2):109-126.

Henkel R. The impact of oxidants on sperm function. 2005. Androlologia 37(6):205-206.

Hrudka F. 1987. Cytochemical and ultracytochemical demonstration of cytochrome-c oxidase in spermatozoa and dynamics of changes accompanying ageing or induced by stress. Int. J. Androl. 10(6):809-828.

Ishizuka B., Kuribayashi Y., Murai K., Amemiya A. \& Itoh M.T. 2000. The effect of melatonin on in vitro fertilization and embryo development in mice. J. Pineal Res. 28(1):48-51.

Khalil W.A., Marei W.F. \& Khalid M. 2013. Protective effects of antioxidants on linoleic acid-treated bovine oocytes during maturation and subsequent embryo development. Theriogenology 80(2):161-168.

Köppen-Geiger Peel M.C., Finlayson B.L. \& McMahon T.A. 2007. Updated world map of the Köppen-Geiger climate classification. Hydrol. Earth Syst. Sci. 11:1633-1644.

Lei X.Y., Zhu R.Y., Zhang G.Y. \& Dai Y.R. 2004. Attenuation of cold-induced apoptosis by exogenous melatonin in carrot suspension cells: the possible involvement of polyamines. J. Pineal Res. 36(2):126-131.

Leon J., Acuña-Castroviejo D., Sainz R.M., Mayo J.C., Tan D.X. \& Reiter R.J. 2004. Melatonin and mitochondrial function. Life Sci. 75(7):765-790.

Lopez A., García J.A., Escames G., Venegas C., Ortiz F., López L.C. \& AcuñaCastroviejo D. 2009. Melatonin protects the mitochondria from oxidative damage reducing oxygen consumption, membrane potential, and superoxide anion production. J. Pineal Res. 46(2):188-198.

Maia M.S., Bicudo S.D., Azevedo H.C., Sicherle C.C., Sousa D.B. \& Rodello L. 2009. Motility and viability of ram sperm cryopreserved in a Trisegg yolk extender supplemented with anti-oxidants. Small Rumin. Res. 85(2):85-90. 
Martinez-Pastor F., Aisen E., Fernández-Santos M.R., Esteso M.C., MarotoMorales A., García-Álvez 0. \& Garde J.J. 2009. Reactive oxygen species generators affect quality parameters and apophysis markers differently in red deer spermatozoa. Reproduction 137(2):225-235.

Martín M., Macías M., Escames G., León J. \& Acuña-Castroviejo D. 2000. Melatonin but not vitamins $\mathrm{C}$ and $\mathrm{E}$ maintains glutathione homeostasis in t-butyl hydroperoxide-induced mitochondrial oxidative stress. FASEB J. 14(12):1677-1679.

Mata-Campuzano M., Alvarez-Rodríguez M., Del Olmo E., Fernández-Santos M.R., Garde J.J. \& Martínez-Pastor F. 2012. Quality, oxidative markers and DNA damage (DNA) fragmentation of red deer thawed spermatozoa after incubation at $37^{\circ} \mathrm{C}$ in presence of several antioxidants. Theriogenology 78(5):1005-1019.

Miki K. 2007. Energy metabolism and sperm function. Soc. Reprod. Fertil. (Suppl.) 65:309-325.

Moce E. \& Graham J.K. 2008. In vitro evaluation of sperm quality. Anim. Reprod. Sci. 105(1/2):104-118.

Moraes E.A., Matos W.C.G., Graham J.K. \& Ferrari Junior W.D. 2015. Cholestanol-loaded-cyclodextrin improve the quality of stallion spermatozoa after cryopreservation. Anim. Reprod. Sci. 158:19-24.

NRC 2000. Minerals, p.54-74. In: National Research Council (Ed.), Nutrient Requirements of Beef Cattle. National Academic Press, Washington, DC,

Ohkawa H., Ohishi N. \& Yagi K. 1979. Assay for lipid peroxides in animal tissues by thiobarbituric acid reaction. Anal. Biochem. 95(2):351-358.

Perumal P., Vupru K. \& Rajkhowa C. 2013. Effect of addition of taurine on the liquid storage $\left(5^{\circ} \mathrm{C}\right)$ of mithun (Bos frontalis) semen. Vet. Med. Int. 2013(4):1-7.

Peyrot F. \& Ducrocq C. 2008. Potential role of tryptophan derivatives in stress responses characterized by the generation of reactive oxygen and nitrogen species. J. Pineal Res. 45(3):235-246.

Rao M.V. \& Gangadharan B. 2008. Antioxidative potential of melatonin against mercury induced intoxication in spermatozoa in vitro. Toxicol. In Vitro 22(4):935-942.
Reiter R.J., Tan D.X., Osuna C. \& Gitto E. 2000. Actions of melatonin in the reduction of oxidative stress - A review. J. Biomed. Sci. 7(6):444-458.

Reiter R.J., Tan D.X. \& Terron M.P. 2007. Melatonin and its metabolites: new findings regarding their production and their radical scavenging actions. Acta Biochim. Pol. 54(1):1-9.

Santos M.A.M., Gradela A., Moraes E.A., Souza W.L., Alves N.G., Costa J.M.S. \& Matos W.C.G. 2015. Características do sêmen a fresco e descongelado de garanhões da raça Nordestina. Pesq. Vet. Bras. 35(11):925-932.

Sariozkan S., Bucak M.N., Tuncer P.B., Taşdemir U., Kinet H. \& Ulutaş P.A. 2010. Effects of different extenders and centrifugation/washingon postthaw microscopic-oxidative stress parameters and fertilizing ability of Angora buck sperm. Theriogenology 73(3):316-323.

SAS System for Windows (Statistical Analysis System) 2002-2008. Version 9.2. SAS Institute Inc., Cary, USA.

Shoae A. \& Zamiri M.J. 2008. Effect of butylated hydroxytoluene on bull spermatozoa frozen in egg yolk-citrate extender. Anim. Reprod. Sci. 104(2/4):414-418.

Sikka S.C. 1996. Oxidative stress and role of antioxidants in normal and abnormal sperm function. Front. Biosci. 1:78-86.

Smith R., Vantman D., Ponce J., Escobar J. \& Lissi E. 1996. Total antioxidant capacity of human seminal plasma. Hum. Reprod. 11(8):1655-1660.

Souza W.L., Lima D.I.B., Moraes E.A., Costa J.M.S., Torres L.R.C., Coelho V.G. \& Magalhaes L.M.V. 2015. Adição de diferentes concentrações de crioprotetores e gema de ovo sobre a motilidade espermática progressiva de ovinos após a criopreservação. Anais XXV Congresso Brasileiro de Zootecnia, Fortaleza, CE, p.1-3.

Tan D.X., Reiter R.J. \& Manchester L.C. 2002. Chemical and physical properties and potential mechanisms: melatonin as a broad spectrum antioxidant and free radical scavenger. Curr. Top. Med. Chem. 2(2):181-197.

Venegas C., García J.A., Escames G., Ortiz F., López A., Doerrier C., GarcíaCorzo L., López L.C., Reiter R.J. \& Acuña-Castroviejo D. 2012. Extrapineal melatonin: analysis of its subcellular distribution and daily fluctuations. J. Pineal Res. 52(2):217-227. 